\title{
Pemantauan Parameter Fisika dan Kimia pada Akuademineral di Laboratorium Kimia Anorganik, Departemen Kimia, Fakultas MIPA, UGM
}

\author{
Wahyu Nugroho ${ }^{1}$ \\ ${ }^{1}$ Laboratorium Kimia Anorganik, Fakultas MIPA, Universitas Gadjah Mada. \\ Email:wahyu nugroho@ugm.ac.id
}

Submisi: 19 Agustus 2019; Penerimaan: 19 Agustus 2020

\begin{abstract}
ABSTRAK
Telah dilakukan pengujian parameter fisika dan kimia terhadap akuademineral yang ada di Laboratorium Kimia Anorganik. Kegiatan ini bertujuan untuk memastikan kualitas akuademineral yang ada di Laboratorioum. Pengujian dilakukan terhadap parameter fisika (seperti : bau, zat terlarut, kekeruhan, rasa dan suhu), dan parameter kimia (Seperti : $p H$, kadar kation, gas-gas terlarut, zat organik, pestisida dan detergen). Metode yang digunakan mengacu pada metode uji SNI dan APHA tentang air bersih. Hasil pengujian menunjukkan semua parameter kimia dan fisika akuademineral memenuhi standar SNI dan lebih baik dibandingkan dengan akuademineral yang ada di pasaran. Akuademineral yang ada di Laboratorium Kimia Anorganik memiliki kualitas yang baik dan layak digunakan untuk kegiatan penelitian dan praktikum di laboratorium.
\end{abstract}

Kata kunci : Parameter fisika; parameter kimia; akuademineral; SNI; Kimia Anorganik.

\section{PENDAHULUAN}

Laboratorium Kimia Anorganik merupakan laboratorium yang bidang penelitiannya banyak di bidang kimia material dan kimia lingkungan. Akuademineral merupakan bahan umum yang sangat vital dalam suatu kegiatan penelitian di laboratorium [1]. Akuademineral berfungsi sebagai pelarut universal yang dibutuhkan untuk pembuatan larutan suatu bahan bahan kimia yang selanjutnya digunakan untuk bahan penelitian, baik di bidang kimia material maupun kimia lingkungan [1].

Laboratorium Kimia Anorganik mempunyai satu unit alat pembuat akuademineral dimana alat ini merupakan modifikasi alat pembuatan akuades yang difokuskan pada penghilangan mineralmineral yang terlarut dalam air. Alat tersebut merupakan hasil dari kegiatan Hibah Inovatif Tenaga Kependidikan tahun 2016. Pada tahun 2017 alat tersebut sudah disempurnakan dengan penambahan sistem pengamanan otomatis. Alat pembuat akuademineral tersebut bekerja secara sederhana yaitu umpan air dilewatkan ke dalam beberapa tabung penyaring yang dilengkapi dengan sistem membran sehingga mineral-mineral pengotor akan tertahan dan dialirkan ke saluran pembuangan sehingga akan diperoleh produk akhir air yang bebas dari mineral pengotori. Akuademineral yang dihasilkan ditampung dalam bak penyimpanan.

Alat pembuat akuademineral yang ada sudah beroperasi dengan baik dan sudah mampu mencukupi kebutuhan akuademineral sebagai ganti akuades untuk kegiatan penelitian di Laboratorium Kimia Anorganik. Akuademineral yang dihasilkan perlu ada kontrol kualitas secara berkala untuk menjaga mutu dari akuademineral yang dihasilkan [2]. Kualitas akuademineral yang digunakan akan sangat menentukan hasil dari penelitian- 
penelitian yang ada di laboratorium kimia anorganik. Kualitas pelarut universal, dalam hal ini akuademineral yang baik akan mengurangi faktor kesalahan dan proses penelitian sehingga diharapkan akan meningkatkan kualitas hasil penelitian [3].

Pada kegiatan ini kami mengusul tema untuk pemantauan kualitas akuademineral di Laboratorium Kimia Anorganik pada pengukuran parameter fisika dan parameter kimia. Parameter fisika meliputi TDS, bau, warna, kekeruhan, rasa, suhu, dan rasa [4]. Parameter kimia meliputi $\mathrm{pH}$, zat-zat organik, logam-logam berat, detergen, senyawa hidrokarbon dan gas-gas terlarut [4]. Nilai pengukuran parameter-parameter tersebut dibandingkan dengan parameter Standar Nasional Indonesia dan American Public Health Association (APHA). Hasil yang diperoleh digunakan untuk mengetahui kualitas akuademineral yang ada di Laboratorium Kimia Anorganik. Apabila ada parameter yang tidak sesuai dengan standar, dapat digunakan sebagai data acuan pengembangan dan perbaikan alat pembuat akuademineral.

\section{METODOLOGI}

Pemantauan kualitas akuade-mineral dilakukan terhadap kedua produk hasil dan dibandingkan dengan dua produk sejenis yang ada di pasaran. Kedua produk dari pasaran selanjutnya dinamakan Pembanding I dan Pembanding II. Keempat sampel diuji keseluruhan parameter fisika dan parameter kimia yang bisa dilakukan. Pengujian dilakukan di Balai Besar Teknik Kesehatan Lingkungan dan Pengendalian Penyakit Yogyakarta. Standar pengujian mengacu pada Standar Nasional Indonesia [4] dan American Public Health Association (APHA) [5]. Parameter fisika dan metode uji yang dilakukan tercantum pada Tabel 1 , sedangkan parameter kimia dan metode uji yang digunakan tercantum pada Tabel 2 .

Tabel 1. Parameter fisika dan metode metode uji yang digunakan

\begin{tabular}{|c|c|c|} 
No & Parameter & Metode uji \\
\hline 1 & Bau & $\begin{array}{c}\text { In House Methode : } \\
\text { Organoleptik }\end{array}$ \\
\hline 2 & TDS & $\begin{array}{c}\text { In House Methode : Cara } \\
\text { uji dengan TDS meter }\end{array}$ \\
\hline 3 & Kekeruhan & $\begin{array}{c}\text { SNI 06-6989.25-2005: } \\
\text { Cara uji kekeruhan } \\
\text { dengan nefelometer }\end{array}$ \\
\hline 4 & Rasa & $\begin{array}{r}\text { In House Methode : } \\
\text { Organoleptik }\end{array}$ \\
\hline 6 & Warna & $\begin{array}{c}\text { SNI 06-6989.23-2005: } \\
\text { Cara uji suhu dengan } \\
\text { termometer }\end{array}$ \\
\hline & Suhu & $\begin{array}{r}\text { SNI warna secara } \\
\text { spektrofotometri }\end{array}$ \\
\hline
\end{tabular}

Tabel 2. Parameter Kimia dan metode metode uji yang digunakan

\begin{tabular}{|c|c|c|c|c|c|}
\hline No & Parameter & Metode uji & No & Parameter & Metode uji \\
\hline 1 & $\mathrm{pH}$ & $\begin{array}{c}\text { SNI 06-6989.11-2004: } \\
\text { Cara uji pH dengan pH } \\
\text { meter }\end{array}$ & 5 & $\begin{array}{c}\text { Mangan } \\
\text { (Mn) }\end{array}$ & $\begin{array}{c}\text { SNI 6989.5-2009 : Cara } \\
\text { uji mangan (Mn) secara } \\
\text { Spektrofotometri Serapan } \\
\text { atom (SSA) }\end{array}$ \\
\hline 2 & Besi (Fe) & $\begin{array}{c}\text { SNI 6989.4.2009: Cara } \\
\text { uji besi (Fe) secara } \\
\text { Spektrofotometri Serapan } \\
\text { atom (SSA) }\end{array}$ & 6 & Nitrat & $\begin{array}{c}\text { APHA 2012, Section 4500 } \\
- \text { NO3B : Cara uji nitrat } \\
\text { secara spektrofotometer }\end{array}$ \\
\hline 3 & Fluorida (F) & $\begin{array}{c}\text { SNI 06-6989.29-2005: } \\
\text { Cara uji fluorida (F-) } \\
\text { secara spektrofotometri } \\
\text { dengan SPADNS }\end{array}$ & 7 & Nitrit & $\begin{array}{c}\text { SNI 06-6989.9-2004: } \\
\text { Cara uji nitrit (NO2-N) } \\
\text { secara spektrofotometri }\end{array}$ \\
\hline Kesadahan & $\begin{array}{c}\text { SNI 06-6989.12-2004: } \\
\text { Cara uji kesadahan total } \\
\text { kalsium (Ca) dengan } \\
\text { metode titrimetri }\end{array}$ & 8 & $\begin{array}{c}\text { Sianida } \\
\text { (CN) }\end{array}$ & $\begin{array}{c}\text { SNI 6989.77-2011 : Cara } \\
\left.\text { uji sianida total (CN }{ }^{-}\right) \\
\text {secara spektrofotometri }\end{array}$ \\
\hline
\end{tabular}


W. Nugroho/ Vol 2 (3) 2020, 35-40

Tabel 2 Lanjutan..

\begin{tabular}{|c|c|c|c|c|c|}
\hline No & Parameter & Metode uji & No & Parameter & Metode uji \\
\hline 9 & Deterjen & $\begin{array}{l}\text { SNI 06-6989.51-2005: } \\
\text { Cara uji kadar surfaktan } \\
\text { anionik dengan } \\
\text { spektrofotometer }\end{array}$ & 15 & $\begin{array}{l}\text { Selenium } \\
\text { (Se) }\end{array}$ & $\begin{array}{c}\text { APHA 2012, Section } 3120 \\
\text { - B : Cara uji selenium } \\
\text { dengan Inductively } \\
\text { Plasma Method (ICP) }\end{array}$ \\
\hline 10 & Pestisida & $\begin{array}{l}\text { In House Methode (tidak } \\
\text { dilakukan) }\end{array}$ & 16 & Seng $(Z n)$ & $\begin{array}{c}\text { SNI 6989.7-2009 : Cara } \\
\text { uji seng (Zn) secara } \\
\text { Spektrofotometri Serapan } \\
\text { Atom (SSA) }\end{array}$ \\
\hline 11 & $\begin{array}{l}\text { Air Raksa } \\
\qquad(\mathrm{Hg})\end{array}$ & $\begin{array}{c}\text { SNI 6989.78-2011 : Cara } \\
\text { uji raksa }(\mathrm{Hg}) \text { secara } \\
\text { Spektrofotometri Serapan } \\
\text { Atom (SSA) }\end{array}$ & 17 & Sulfat & $\begin{array}{c}\text { SNI } 6989.20 .2009 \text { : Cara } \\
\text { uji sulfat (SO4 2-) secara } \\
\text { turbidimetri }\end{array}$ \\
\hline 12 & Arsen (As) & $\begin{array}{c}\text { In House Methode : } \\
\text { Pengujian dengan } \\
\text { Spektrofotometri Serapan } \\
\text { Atom }\end{array}$ & 18 & Timbal (Pb) & $\begin{array}{c}\text { SNI 6989.46-2005 : Cara } \\
\text { uji kadar timbal (Pb) } \\
\text { dengan Spektrofotometer } \\
\text { Serapan Atom }\end{array}$ \\
\hline 13 & $\begin{array}{l}\text { Kadmium } \\
\quad(\mathrm{Cd})\end{array}$ & $\begin{array}{c}\text { SNI 06-6989.38-2005: Uji } \\
\text { kadar kadmium (Cd) } \\
\text { denganSpektrofotometer } \\
\text { Serapan Atom }\end{array}$ & 19 & Benzen & $\begin{array}{l}\text { In House Methode (tidak } \\
\text { dilakukan) }\end{array}$ \\
\hline 14 & $\begin{array}{l}\text { Kromium } \\
(\mathrm{Cr} 6+)\end{array}$ & $\begin{array}{l}\text { APHA 2012, Section } 3500 \\
\text { - CrB : Cara Uji kromium } \\
\text { dengan Spektrofotometri } \\
\text { Serapan Atom }\end{array}$ & 20 & $\begin{array}{c}\text { Zat Organik } \\
(\mathrm{KMnO} 4)\end{array}$ & $\begin{array}{c}\text { SNI 06-6989.22-2004 : } \\
\text { Cara uji nilai } \\
\text { permanganat secara } \\
\text { titrimetri }\end{array}$ \\
\hline
\end{tabular}

\section{HASIL DAN PEMBAHASAN}

Alat pembuat akuademineral yang di Laboratorium Kimia Anorganik menghasilkan dua produk. Produk yang pertama merupakan air yang sudah melewati penyaring biasa, kolom pertukaran ion, dan tiga penyaring membran. Produk kedua merupakam kelanjutan proses dari produk pertama, dimana produk pertama dilewatkan lagi tiga penyaring membran. Sebagai pembanding digunakan dua produk akuadest bebas ion yang ada di pasaran yang dalam pembahasan ini diberi nama Pembanding 1 dan Pembanding 2

Hasil pengujian Hasil 1, Hasil 2, Pembanding 1 dan Pembanding 2 dibagi menjadi dua kategori, parameter fisika dan parameter kimia. Hasil pengujian parameter fisika dapat dilihat pada Tabel 3. Pengujian parameter fisika terdapat enam parameter yang diuji. Parameter bau, rasa, dan suhu, hasil yang didapat dari keempat sampel sama. Parameter TDS untuk hasil 1 menunjukkan nilai yang paling tinggi, yaitu $52 \mathrm{mg} / \mathrm{L}$, sedangkan untuk sampel yang lain hasilnya sama $10 \mathrm{mg} / \mathrm{L}$. Hal tersebut menunjukkan partikel terlarut dalam hasil 1 paling banyak dibanding dengan sampel lainnya, tetapi hal tersebut masih jauh dari kadar maksimum yang diperbolehkan, yaitu 1000 mg/L. Begitu juga dengan parameter kekeruhan dan warna, hasil 1 mempunyai nilai yang paling besar yaitu 1 NTU untuk parameter kekeruhan dan 3 TCU untuk parameter warna. Hasil 1 dalam hal parameter fisika mempunyai kualitas terendah dibanding sampel lainnya. Meskipun nilai parameternya kalah dibanding dengan sampel lainnya, sampel Hasil 1 masih sangat layak digunakan dalam kegiatan penelitian/pendidikan dikarenakan masih masuk spesifikasi atau masih jauh dari kadar maksimum yang diperbolehkan. 
Tabel 3. Hasil pengujian parameter fisika

\begin{tabular}{|c|c|c|c|c|c|c|c|c|}
\hline \multirow[b]{2}{*}{ No } & \multirow[b]{2}{*}{ Parameter } & \multirow[b]{2}{*}{ Satuan } & \multicolumn{4}{|c|}{ Jenis Air } & \multirow{2}{*}{$\begin{array}{c}\text { Kadar } \\
\text { maks }\end{array}$} & \multirow[b]{2}{*}{ Metode uji } \\
\hline & & & Hasil 1 & Hasil 2 & $\begin{array}{c}\text { Pembanding } \\
1\end{array}$ & $\begin{array}{c}\text { Pembanding } \\
2\end{array}$ & & \\
\hline 1 & Bau & - & $\begin{array}{c}\text { Tak } \\
\text { berbau }\end{array}$ & $\begin{array}{c}\text { Tak } \\
\text { berbau }\end{array}$ & Tak berbau & Tak berbau & $\begin{array}{c}\text { Tak } \\
\text { berbau }\end{array}$ & $\begin{array}{l}\text { In House } \\
\text { Methode }\end{array}$ \\
\hline 2 & TDS & $\mathrm{mg} / \mathrm{L}$ & 52 & 10 & 10 & 10 & 1000 & $\begin{array}{l}\text { In House } \\
\text { Methode }\end{array}$ \\
\hline 3 & Kekeruhan & NTU & 1 & $<1$ & $<1$ & $<1$ & 25 & $\begin{array}{c}\text { SNI 06- } \\
6989.25- \\
2005\end{array}$ \\
\hline 4 & Rasa & - & $\begin{array}{c}\text { Tak } \\
\text { berasa }\end{array}$ & $\begin{array}{c}\text { Tak } \\
\text { berasa }\end{array}$ & Tak berasa & Tak berasa & $\begin{array}{c}\text { Tak } \\
\text { berasa }\end{array}$ & $\begin{array}{l}\text { In House } \\
\text { Methode }\end{array}$ \\
\hline 5 & Suhu & ${ }^{\circ} \mathrm{C}$ & 25.6 & 25.6 & 25.6 & 25.6 & $\begin{array}{l}\text { Suhu } \\
\text { udara } \\
\pm 3^{\circ} \mathrm{C} \\
\end{array}$ & $\begin{array}{c}\text { SNI 06- } \\
6989.23- \\
2005 \\
\end{array}$ \\
\hline 6 & Warna & TCU & 3 & 1 & 1 & 1 & 50 & $\begin{array}{c}\text { SNI } \\
6989.80- \\
2011\end{array}$ \\
\hline
\end{tabular}

Pengujian parameter yang selanjutnya adalah parameter kimia. Pengujian parameter kimia ini meliputi 20 parameter, dari parameter $\mathrm{pH}$, logamlogam, kesadahan air, detergen, gas-gas terlarut, sianida, pestisida, air raksa, zat-zat organik dan lain sebagainya. Logam-logam, seperti logam besi(Fe), Mangan(Mn), cadmium(Cd), Kromium(Cr), selenium(Se), Seng $(\mathrm{Zn})$, dan Timbal(Pb). Kesadahan yang dianalisis merupakan garam kalsium karbonat $\left(\mathrm{CaCO}_{3}\right)$. Gas-gas terlarut meliputi nitrat, nitrit, dan sulfat. Zat organik ditentukan dengan mengukur jumlah kalium permanganat yang diperlukan untuk mengoksidadi zat organik per liter sampel. Hasil pengujian ditampilkan dalam Tabel 4.
Hasil pengujian parameter kimia pada parameter detergen menunjukkan sampel pembanding 1 dan pembanding 2 sudah melebihi kadar maksimum yang diperbolehkan, yaitu $0.1305 \mathrm{mg} / \mathrm{L}$ untuk sampel pembanding 1 dan $0.0536 \mathrm{mg} / \mathrm{L}$ untuk sampel pembanding 2 , sedang untuk kadar maksimum yang diperbolehkan 0.05 $\mathrm{mg} / \mathrm{L}$. Hal ini disebabkan oleh dua kemungkinan, yaitu dari kontainer atau wadah yang digunakan atau dari produk asalnya sudah out of spec. Parameter detergen untuk sampel Hasil $10.0197 \mathrm{mg} / \mathrm{L}$ dan sampel Hasil 20.0405 mg/L. Hasil tersebut masih cukup jauh dari kadar maksimum yang diperbolehkan.

Tabel 4. Hasil Pengujian Parameter Kimia

\begin{tabular}{|c|c|c|c|c|c|c|c|c|}
\hline \multirow{2}{*}{ No } & \multirow{2}{*}{ Parameter } & \multirow{2}{*}{ Satuan } & \multicolumn{4}{|c|}{ Jenis Air } & \multirow{2}{*}{$\begin{array}{c}\text { Kadar } \\
\text { maks }\end{array}$} & \multirow{2}{*}{ Metode uji } \\
\hline & & & Hasil 1 & $\begin{array}{l}\text { Hasil } \\
2\end{array}$ & $\begin{array}{c}\text { Pembanding } \\
1\end{array}$ & $\begin{array}{c}\text { Pembanding } \\
2\end{array}$ & & \\
\hline 1 & $\mathrm{pH}$ & - & 6.8 & 6.8 & 6.8 & 6.8 & $6,5-8,5$ & $\begin{array}{c}\text { SNI 06- } \\
6989.11-2004\end{array}$ \\
\hline 2 & Besi (Fe) & $\mathrm{mg} / \mathrm{L}$ & 0.0339 & 0.02 & 0.02 & 0.0269 & 1 & $\begin{array}{c}\text { SNI } \\
6989.4 .2009\end{array}$ \\
\hline 3 & Fluorida (F) & $\mathrm{mg} / \mathrm{L}$ & 0.2446 & 0.06 & 0.06 & 0.0643 & 1.5 & $\begin{array}{c}\text { SNI 06- } \\
6989.29-2005\end{array}$ \\
\hline 4 & $\begin{array}{c}\text { Kesadahan } \\
\mathrm{CaCO}_{3}\end{array}$ & $\mathrm{mg} / \mathrm{L}$ & 31.84 & $\begin{array}{c}< \\
0,91\end{array}$ & $<0,91$ & $<0,91$ & 500 & $\begin{array}{c}\text { SNI 06- } \\
6989.12-2004\end{array}$ \\
\hline
\end{tabular}


Tabel 4 Lanjutan...

\begin{tabular}{|c|c|c|c|c|c|c|c|c|}
\hline \multirow[b]{2}{*}{ No } & \multirow[b]{2}{*}{ Parameter } & \multirow{2}{*}{$\begin{array}{c}\text { Satua } \\
\mathrm{n}\end{array}$} & \multicolumn{4}{|c|}{ Jenis Air } & \multirow{2}{*}{$\begin{array}{l}\text { Kadar } \\
\text { maks }\end{array}$} & \multirow[b]{2}{*}{ Metode uji } \\
\hline & & & $\begin{array}{c}\text { Hasil } \\
1\end{array}$ & $\begin{array}{l}\text { Hasil } \\
2\end{array}$ & $\begin{array}{c}\text { Pembandin } \\
\mathrm{g} 1\end{array}$ & $\begin{array}{l}\text { Pembandin } \\
\text { g } 2\end{array}$ & & \\
\hline 5 & $\begin{array}{l}\text { Mangan } \\
(\mathrm{Mn})\end{array}$ & $\mathrm{mg} / \mathrm{L}$ & $\begin{array}{c}< \\
0,010 \\
1\end{array}$ & $\begin{array}{c}< \\
0,010 \\
1\end{array}$ & $<0,0101$ & $<0,0101$ & 0.5 & SNI 6989.5-2009 \\
\hline 6 & Nitrat & $\mathrm{mg} / \mathrm{L}$ & 0.57 & 0.03 & 0.03 & $<0,01$ & 10 & $\begin{array}{c}\text { APHA 2012, Section } \\
4500 \text { - NO3B }\end{array}$ \\
\hline 7 & Nitrit & $\mathrm{mg} / \mathrm{L}$ & $\begin{array}{c}0.006 \\
9\end{array}$ & $\begin{array}{c}< \\
0,000 \\
4\end{array}$ & $<0,0004$ & $<0,0004$ & 1 & SNI 06-6989.9-2004 \\
\hline 8 & $\begin{array}{l}\text { Sianida } \\
\text { (CN) }\end{array}$ & $\mathrm{mg} / \mathrm{L}$ & $\begin{array}{c}< \\
0,007 \\
0\end{array}$ & $\begin{array}{c}< \\
0,007 \\
0\end{array}$ & $<0,0070$ & $<0,0070$ & 0.1 & SNI 6989.77-2011 \\
\hline 9 & Deterjen & $\mathrm{mg} / \mathrm{L}$ & $\begin{array}{c}0.019 \\
7\end{array}$ & $\begin{array}{c}0.040 \\
5\end{array}$ & 0.1305 & 0.0536 & 0.05 & $\begin{array}{c}\text { SNI 06-6989.51- } \\
2005 \\
\end{array}$ \\
\hline 10 & Pestisida & $\mathrm{mg} / \mathrm{L}$ & - & - & - & - & 0.1 & In House Methode \\
\hline 11 & $\begin{array}{l}\text { Air Raksa } \\
(\mathrm{Hg})\end{array}$ & $\mathrm{mg} / \mathrm{L}$ & - & - & - & - & 0.001 & SNI 6989.78-2011 \\
\hline 12 & Arsen (As) & $\mathrm{mg} / \mathrm{L}$ & $<$ & $<$ & $<0,005$ & $<0,005$ & 0.05 & In House Methode \\
\hline 13 & $\begin{array}{l}\text { Kadmium } \\
\text { (Cd) }\end{array}$ & $\mathrm{mg} / \mathrm{L}$ & $\begin{array}{c}< \\
0,000 \\
4\end{array}$ & $\begin{array}{c}< \\
0,000 \\
4\end{array}$ & $<0,0004$ & $<0,0004$ & 0.005 & $\begin{array}{l}\text { SNI 06-6989.38- } \\
2005\end{array}$ \\
\hline 14 & $\begin{array}{l}\text { Kromium } \\
\left(\mathrm{Cr}^{6+}\right)\end{array}$ & $\mathrm{mg} / \mathrm{L}$ & $\begin{array}{c}<< \\
0,001 \\
4\end{array}$ & $\begin{array}{c}<< \\
0,001 \\
4\end{array}$ & $<0,0014$ & $<0,0014$ & 0.05 & $\begin{array}{c}\text { APHA 2012, Section } \\
3500 \text { - CrB }\end{array}$ \\
\hline 15 & $\begin{array}{l}\text { Selenium } \\
\text { (Se) }\end{array}$ & $\mathrm{mg} / \mathrm{L}$ & $\begin{array}{c}< \\
0,000 \\
6\end{array}$ & $\begin{array}{c}< \\
0,000 \\
6\end{array}$ & $<0,0006$ & $<0,0006$ & 0.01 & $\begin{array}{c}\text { APHA 2012, Section } \\
3120 \text { - B }\end{array}$ \\
\hline 16 & Seng $(Z n)$ & $\mathrm{mg} / \mathrm{L}$ & $\begin{array}{c}< \\
0,008 \\
3\end{array}$ & $\begin{array}{c}0.037 \\
5\end{array}$ & $<0,0083$ & $<0,0083$ & 15 & SNI 6989.7-2009 \\
\hline 17 & Sulfat & $\mathrm{mg} / \mathrm{L}$ & 11 & 5 & 5 & 5 & 400 & SNI 6989.20.2009 \\
\hline 18 & Timbal (Pb) & $\mathrm{mg} / \mathrm{L}$ & $\begin{array}{c}< \\
0,000 \\
8\end{array}$ & $\begin{array}{c}< \\
0,000 \\
8\end{array}$ & $<0,0008$ & $<0,0008$ & 0.05 & SNI 6989.46-2005 \\
\hline 19 & Benzen & $\mathrm{mg} / \mathrm{L}$ & - & - & - & - & 0.01 & In House Methode \\
\hline 20 & $\begin{array}{l}\text { Zat Organik } \\
\left(\mathrm{KMnO}_{4}\right)\end{array}$ & $\mathrm{mg} / \mathrm{L}$ & 3.16 & 2.53 & 2.53 & 2.53 & 10 & $\begin{array}{c}\text { SNI 06-6989.22- } \\
2004\end{array}$ \\
\hline
\end{tabular}

Hasil pengujian logam-logam menunjukkan beberapa parameter untuk Hasil 1 menghasilkan nilai yang lebih besar dibandingkan dengan sampel lainnya, seperti besi(Fe) untuk sampel hasil 1 $0.0339 \mathrm{mg} / \mathrm{L}$, sedangkan sampel lainnya $0.02 \mathrm{mg} / \mathrm{L}$. Fluorida(F) untuk sampel Hasil $10.2446 \mathrm{mg} / \mathrm{L}$, sedangkan sampel lainnya sekitar $0.06 \mathrm{mg} / \mathrm{L}$. Meskipun nilai parameter besi dan fluorida mempunyai nilai yang lebih besar dibandingkan dengan sampel lainnya, sampel hasil 1 masih dibawah kadar maksimum yang diperbolehkan.
Kadar maksimum yang diperbolehkan untuk parameter besi $1 \mathrm{mg} / \mathrm{L}$ dan parameter fluorida $1.5 \mathrm{mg} / \mathrm{L}$. Anomali terjadi pada hasil parameter Seng, dimana sampel Hasil 2 menunjukkan nilai yang paling tinggi, yaitu $0.0375 \mathrm{mg} / \mathrm{L}$, sedangkan sampel yang lain $<0.0083 \mathrm{mg} / \mathrm{L}$. Hal ini menunjukkan adanya penambahan logam seng selama proses penyaringan atau proses di kolom resin penukar ion. Kemungkinan besar adanya nilai seng yang tinggi ini disebabkan adanya bahan dari seng di kolom penukar ion. Hasil tersebut sebenarnya masih jauh 
dari kadar yang diperbolehkan, yaitu 15 $\mathrm{mg} / \mathrm{L}$, sehingga untuk hasil ini tidak mempengaruhi kualitas akuademineral sampel Hasil 2. Hasil pengujian parameterparameter logam lainnya, seperti Mangan, Arsen, Kadmium, Kromium, dan Timbal mempunyai nilai yang sama dan semua masih jauh dibawah kadar maksimum yang diperbolehkan.

Parameter kesadahan air, dalam hal ini garam $\mathrm{CaCO}_{3}$ yang terkandung dalam sampel menunjukkan dalam sampel Hasil 1 mengandung nilai yang tertinggi, yaitu $31.84 \mathrm{mg} / \mathrm{L}$, sedangkan sampel yang lain mempunyai nilai parameter yang sama, yakni $<0.91 \mathrm{mg} / \mathrm{L}$. Hal tersebut menunjukkan ion-ion $\mathrm{Ca}^{2+}$ belum sepenuhnya tersaring oleh penyaring membran maupun resin penukar ion. Meskipun nilai parameter Hasil 1 paling tinggi tetapi masih jauh dari kadar yang diperbolehkan, yaitu $500 \mathrm{mg} / \mathrm{L}$, jadi akuadimeral Hasil 1 masih mempunyai kualitas kesadahan yang bagus dan layak digunakan.

Gas-gas terlarut dari keempat sampel menunjukkan kualitas sampel yang masih sangat bagus, hanya saja nilainya bervariasi. Untuk sampel Hasil 1 masih mempunyai nilai yang paling tinggi; Nitrat $0.57 \mathrm{mg} / \mathrm{L}$, Nitrit $0.0069 \mathrm{mg} / \mathrm{L}$, dan Sulfat 11 $\mathrm{mg} / \mathrm{L}$. Hasil tersebut masih jauh dari kadar maksimum yang diperbolehkan, yaitu Nitrat $10 \mathrm{mg} / \mathrm{L}$, Nitrit $1 \mathrm{mg} / \mathrm{L}$, dan Sulfat $400 \mathrm{mg} / \mathrm{L}$. Hasil tersebut menunjukkan kelayakan sampel Hasil 1 untuk bisa digunakan dalam kegiatan di Laboratorium.

Hasil uji zat organik menunjukkan hasil yang bagus, meskipun nilai hasil pada sampel Hasil 1 paling tinggi, yaitu 3.16 $\mathrm{mg} / \mathrm{L}$, sedangkan sampel yang lain 2.53 $\mathrm{mg} / \mathrm{L}$. Kadar maksimum untuk zat organik yang diperbolehkan adalah $10 \mathrm{mg} / \mathrm{L}$. Hal tersebut menunjukkan sampel Hasil 1 masih dapat digunakan. Beberapa parameter tidak terdeteksi pada pengujian ini. Parameter yang tidak terdeteksi menunjukkan sangat kecilnya kadar parameter tersebut.Parameter yang tidak terdeteksi adalah pestisida, air raksa dan benzena. Pengujian sampel akuademineral yang dilakukan menunjukkan akuademineral yang dihasilkan di Laboratorium Kimia Anorganik, Departemen Kimia, Fakultas Matematika dan IImu Pengetahuan Alam mempunyai kualitas yang bagus dan layak digunakan.

\section{KESIMPULAN}

Kesimpulan dari penelitian ini adalah akuademineral di Laboratorium Kimia Anorganik sudah sesuai dengan standar SNI dan APHA dan layak digunakan untuk kegiatan penelitian dan praktikum

\section{DAFTAR PUSTAKA}

1. Muhaimmin, H.M., Pardi, Lestari, V. 2009. Modifikasi Sistem Sirkulasi Air pada Pembuatan Air Suling Terdemineralisasi. Prosiding Seminar Nasional Sains dan Teknologi Nuklir.

2. Khotimah, H., Anggraeni, E.W., Setianingsih, A., 2017, Karakterisasi Hasil Pengolahan Menggunakan Alat Destilasi, Jurnal Chemurgy, Vol. 01, No.2, Samarinda.

3. Agustini, Sri. 2017. Harmonisasi Standar Nasional (SNI) Air Minum Dalam Kemasan Dan Standar Internasional. Majalah Teknologi Agro Industri (Tegi). Volume 9 No. 2. Palembang.

4. Badan Standardisasi Nasional, 2015, SNI 6241:2015, Standar Nasional Indonesia Air Demineral, Jakarta.

5. APHA. 2012. Standard Method for The Examination of Water and Wastewater. 22nd Ed. American Public Health Association Inc. New York 